\title{
BIỂU HIỆN MỨC Độ THÍCH ÚNG VỚI HOẠT ĐộNG HỌC MÔN ĐỌC HIỄU TIẾNG NƯỚC NGOÀI CỦA SINH VIÊN TRƯờnG ĐẠI HỌC NGOẠI NGŨ̉ - ĐẠI HỌC QUỐC GIA HÀ NỘI
}

\author{
Đặng Thị Lan*
}

\begin{abstract}
Bộ môn Tâm lý - Giáo dục, Truòng Đại học Ngoại ngũu, ĐHQGHN, Phạm Văn Đồng, Cầu Giấy, Hà Nọi, Việt Nam
\end{abstract}

Nhận bài ngày 18 tháng 10 năm 2016

Chỉnh sửa ngày 19 tháng 12 năm 2016; Chấp nhận đăng ngày 05 tháng 01 năm 2017

Tóm tắt: Nghiên cứu đã chỉ ra một số vấn đề lí luận cơ bản như hoạt động học tiếng nước ngoài, mức độ thích ứng với hoạt động học môn đọc hiểu tiếng nước ngoài, biểu hiện mức độ thích ứng với hoạt động học môn đọc hiểu tiếng nước ngoài qua nhận thức bản chất, nội dung cụ thể, tác dụng của năm hành động học cơ bản của môn học và thực hành năm hành động học đó. Kết quả nghiên cứu thực tiễn cho thấy sinh viên Trường Đại học Ngoại ngữ - Đại học Quốc gia Hà Nội đã có hiểu biết cơ bản về bản chất, nội dung cụ thể, tác dụng của các hành động học cơ bản và thực hành có hiệu quả các hành động học đó, tuy rằng kết quả chưa cao. Một số hành động học cơ bản của môn học như chuẩn bị bài học, tiếp thu kiến thức bài học được sinh viên nhận thức và thực hành ở mức độ trung bình; các hành động học cơ bản khác như sử dụng giáo trình và tài liệu tham khảo, chuẩn bị và tiến hành xêmina thì mức độ nhận thức và thực hành của sinh viên còn thấp.

Từ khóa: hoạt động học tiếng nước ngoài, đọc hiểu tiếng nước ngoài, biểu hiện mức độ thích ứng, sinh viên Trường Đại học Ngoại ngữ

\section{1. Đặt vấn đề}

Quá trình học tiếng nước ngoài (TNN), sinh viên (SV) phải học môn lý thuyết tiếng (ngữ pháp, ngữ âm, ngữ nghĩa, ngữ dụng học), môn thực hành tiếng (đọc hiểu, nói, nghe hiểu, viết) và một số môn học khác. Trong các môn thực hành tiếng thì đọc hiểu TNN giữ vai trò quan trọng, giúp SV làm giàu vốn kiến thức TNN, vốn từ vựng và có điều kiện thuận lợi để phát triển các kỹ năng thực hành TNN. Thực tiễn nghiên cứu ở Trường Đại học Ngoại ngữ - Đại học Quốc gia Hà Nội (ĐHQGHN) cho thấy $\mathrm{SV}$ còn thích ứng với hoạt động học môn đọc hiểu TNN ở mức độ thấp. Việc nghiên cứu biểu hiện mức độ thích ứng với hoạt động học môn đọc hiểu TNN qua mặt nhận thức và mặt thực hành các hành động học cơ bản của môn

* ĐT.: 84-985310261, Email: dangthilan65@gmail.com học sẽ giúp chỉ ra một số hành động học được SV nhận thức và bước đầu thực hành tốt hơn, một số hành động học được $\mathrm{SV}$ nhận thức và bước đầu thực hành kém hơn, từ đó có thể đề xuất một số biện pháp nâng cao mức độ thích ứng với hoạt động học môn đọc hiểu TNN cho SV Trường Đại học Ngoại ngũ̃ - ĐHQGHN.

\section{Một số vấn đề lý luận}

2.1. Hoạt động học tiếng nước ngoài và đọc hiểu tiếng nước ngoài

- Hoạt động học tiếng nước ngoài:

Hoạt động học TNN là hoạt động diễn ra theo phương thức xã hội đặc thù, có mục đích, nội dung, chương trình, kế hoạch, phương pháp và hình thức tổ chức học; được người học nhận thức đầy đủ rõ ràng nhằm chiếm lĩnh tri thức ngôn ngữ, hình thành kỹ năng, kỹ xảo 
lời nói TNN và nghiệp vụ chuyên môn theo chuyên ngành đào tạo.

Hoạt động học TNN có những đặc điểm cơ bản là:

Hoạt động học TNN là hoạt động có đối tượng. Đối tượng của hoạt động học TNN là tri thức ngôn ngữ và kỹ năng, kỹ xảo lời nói TNN. Tri thức ngôn ngữ của một ngôn ngũ cụ thể (ngữ âm, từ vựng, ngữ nghĩa và ngữ pháp...) được người học lĩnh hội chủ yếu trong quá trình tiếp thu những vấn đề lý luận. Kỹ năng, kỹ xảo lời nói TNN là các hành động lời nói tương ứng với các tri thức ngôn ngữ, được hình thành thông qua quá trình vận dụng các tri thức ngôn ngữ vào thực tiễn.

Đối tượng của hoạt động học TNN được người học TNN luôn ý thức rõ ràng.

Hoạt động học TNN nhằm làm thay đổi chính chủ thể của nó (phát triển TNN ở người học) chứ không làm thay đổi gì ở đối tượng của hoạt động học TNN (không đưa cái gì mới vào TNN được học).

Hoạt động học TNN vận hành theo co chế lĩnh hội, tức cơ chế tái tạo chứ không phải cơ chế sáng tạo.

Hoạt động học TNN không chỉ hướng tới tiếp thu những tri thức ngôn ngữ, kỹ năng, kỹ xảo lời nói TNN mà còn hướng tới tiếp thu những tri thức của chính bản thân hoạt động học TNN - đó là phương pháp làm việc với TNN (dạy học, dịch thuật, giao tiếp) (Trần Hữu Luyến, 2008).

\section{- Đọc hiểu tiếng nuớc ngoài:}

Theo D.I. Clưtrnhicôva, đọc hiểu TNN "là một quá trình tri giác và xử lý thông tin mang tính tích cực - cái đã được mã hóa bằng những nét chữ theo một hệ thống của ngôn ngữ này hay ngôn ngữ kia" (Dẫn theo Đỗ Thị Châu, 1999).

Đọc hiểu TNN có những đặc điểm đặc trưng cơ bản sau:

Đọc hiểu TNN là một loại hoạt động lời nói nhằm tri giác và thông hiểu ngôn ngữ viết. Quan điểm tâm lý học ngôn ngữ coi đọc hiểu là một quá trình tâm lý biểu hiện tính tích cực hoạt động ngôn ngữ của chủ thể tiếp nhận ngôn ngữ ở hai mặt tri giác ngôn ngữ và thông hiểu ngôn ngữ, là quá trình chuyển từ nghĩa khách quan chứa đựng trong chữ viết thành ý chủ quan của chủ thể tiếp nhận. Tri giác ngôn ngũ là một quá trình tâm lý ngôn ngữ phức tạp với tư cách một hoạt động nhận thức tích cực của chủ thể do nhiều yếu tố chủ quan chi phối như: khả năng tri giác ngôn ngữ, khả năng đọc ngôn ngữ, vốn ngôn ngữ, vốn kinh nghiệm sống, trình độ tư duy... Thông hiểu ngôn ngũ thực chất là quá trình thông hiểu ngữ nghĩa của ngôn ngữ thể hiện trong chữ viết, kí hiệu ngôn ngữ. Có nhiều mức độ thông hiểu ngôn ngữ: hiểu nghĩa bên ngoài, hiểu một số dấu hiệu của nghĩa nhưng chưa bản chất, hiểu dấu hiệu bản chất của nghĩa. Giữa tri giác ngôn ngữ và thông hiểu ngôn ngữ có quan hệ chặt chẽ với nhau, chi phối lẫn nhau trong một quá trình chỉnh thể của hoạt động tiếp nhận ngôn ngữ. Khi đọc hiểu TNN, các tín hiệu ngôn ngữ được thu nhận vào chủ yếu bằng mắt nên cảm giác nhìn chiếm ư thế; đọc hiểu luôn kèm theo sự tái tạo lại ngữ liệu bằng lời nói bên trong (đọc thầm) hoặc lời nói bên ngoài (đọc to). Do đó, cảm giác vận động và cảm giác nghe cũng giữ vai trò quan trọng (Đỗ Thị Châu, 1999).

\subsection{Mức độ thích ưng với hoạt động học môn đọc hiểu tiếng nước ngoài}

Mức độ thích ứng với hoạt động học môn đọc hiểu TNN là phạm vi thay đổi về mặt nhận 
thức, thái độ và hành động của người học đáp ứng với yêu cầu, nhiệm vụ, điều kiện, phương tiện của hoạt động học môn đọc hiểu $\mathrm{TNN}$ và bảo đảm cho họ tiến hành hoạt động học môn đọc hiểu TNN có kết quả (Đặng Thị Lan, 2013).

\subsection{Biểu hiện mức độ thích ứng với hoạt động} họ môn đọc hiểu tiếng nước ngoài của sinh viên Truờng Đại học Ngoại ngũ - ĐHQGHN

Biểu hiện mức độ thích ứng với hoạt động học môn đọc hiểu TNN của SV Trường Đại học Ngoại ngữ - ĐHQGHN được đánh giá qua việc SV nhận thức bản chất, nội dung cụ thể, tác dụng của năm hành động học cơ bản và việc $\mathrm{SV}$ thực hành năm hành động học đó: chuẩn bị bài học, tiếp thu kiến thức bài học, sử dụng giáo trình $(\mathrm{GT})$ và tài liệu tham khảo (TLTK), chuẩn bị và tiến hành xêmina, ôn tập môn đọc hiểu TNN.

\section{- Chuẩn bị bài học môn đọc hiểu TNN:}

Mặt nhận thức: nhận thức đúng chuẩn bị bài học môn đọc hiểu TNN là học từ mới, ôn lại cấu trúc câu có liên quan đến chủ đề bài đọc hiểu, tìm các nguồn tài liệu phục vụ chủ đề bài đọc hiểu và đi sâu vào một chủ đề hẹp do giảng viên qui định; tác dụng của chuẩn bị bài học môn đọc hiểu TNN là giúp SV xác định đúng những nội dung cần tập trung của chủ đề bài đọc hiểu.

Mặt thực hành: chuẩn bị đầy đủ các tài liệu cần thiết cho bài đọc hiểu; xác định mối quan hệ giữa kiến thức cũ với chủ đề bài đọc hiểu; xác định các thành phần của bài đọc hiểu; xác định các kiến thức trọng tâm của bài đọc hiểu; xác định kiến thức chưa rõ hoặc khó hiểu của bài đọc hiểu.

- Tiếp thu kiến thức bài học môn đọc hiểu TNN:

Mặt nhận thức: nhận thức đúng tiếp thu kiến thức bài học môn đọc hiểu TNN là tiếp thu những nội dung mà bản thân nhận thấy cần thiết; tác dụng của tiếp thu tốt kiến thức bài học môn đọc hiểu TNN là giúp SV nắm được nội dung bài đọc hiểu, hiểu ngay trên lớp; trả lời được những câu hỏi của bài đọc hiểu, tóm tắt nội dung bài đọc hiểu thành một đoạn văn ngắn làm tài liệu phục vụ cho việc ôn tập; có được những kiến thức quan trọng về một vấn đề nào đó trong chủ đề bài đọc hiểu và vận dụng nó vào cuộc sống.

Mặt thực hành: lựa chọn cách diễn đạt tóm tắt nội dung bài đọc hiểu theo ý riêng của mình; tiếp thu kịp, đầy đủ và đúng những thông tin bài đọc hiểu; đọc lại nội dung bài đọc hiểu để bổ sung, chỉnh lý những kiến thức đã tiếp thu và đưa ra ý kiến riêng của bản thân về từng nội dung của bài học hiểu.

- Sư dụng GT và TLTK môn đọc hiểu TNN:

Mặt nhận thức: nhận thức đúng sử dụng GT và TLTK môn đọc hiểu TNN là hình thức học tập chủ yếu để tích lũy tri thức ngôn ngữ phục vụ việc học tập và nghiên cứu $\mathrm{TNN}$ nói chung và môn đọc hiểu TNN nói riêng ở trường ĐHNN - ĐHQGHN; tác dụng của sử dụng GT và TLTK môn đọc hiểu TNN là giúp SV tự học TNN theo kiểu nghiên cứu.

Mặt thực hành: đọc đúng trình tự các phần của GT và TLTK; đọc lướt để tìm ý chính, đọc nhanh để tìm các thông tin, đọc suy luận để ghép các thông tin lại cho phù hợp; nhớ, suy nghĩ và vận dụng những điều vừa đọc; lưu giữ thông tin bằng cách ghi vào các tờ giấy nhỏ rời; phân loại thông tin theo từng chủ đề bài đọc hiểu.

- Chuẩn bị và tiến hành xêmina môn đọc hiểu TNN: 
Mặt nhận thức: nhận thức đúng chuẩn bị và tiến hành xêmina môn đọc hiểu TNN là hình thức trao đổi, tranh luận về một chủ đề khoa học có liên quan đến những bài đọc hiểu do SV tổ chức dưới sự hướng dẫn của giảng viên; tác dụng lớn nhất của xêmina môn đọc hiểu TNN là rèn luyện tư duy khoa học và năng lực vận dụng kiến thức.

Mặt thực hành: huy động thông tin từ nhiều nguồn tài liệu; tiếp cận nội dung bài đọc hiểu theo nhiều góc độ khác nhau; chuẩn bị ý kiến trao đổi và tranh luận chủ đề xêmina; thực hiện đúng trình tự các bước chuẩn bị và tiến hành xêmina: nghiên cứu kỹ thông tin, tư liệu có liên quan đến chủ đề xêmina; xác định cấu trúc chủ đề xêmina; sắp xếp, trình bày thông tin theo chủ đề đã định; chuẩn bị ý kiến tham gia tranh luận

\section{- Ôn tập môn đọc hiểu TNN:}

Mặt nhận thức: nhận thức đúng ôn tập môn đọc hiểu TNN là hiểu và nhớ kiến thức các bài đọc hiểu đã học trong mối quan hệ thống nhất hữu cơ giữa chúng; ôn tập môn đọc hiểu TNN đúng cách giúp người học dễ nhớ và dễ hiểu hệ thống các mối quan hệ giữa các kiến thức đã tiếp thu.

Mặt thực hành: làm các bài tập về từ vựng, ngữ pháp có liên quan đến chủ đề bài đọc hiểu; soạn đề cương ôn tập đúng qui định; có phương pháp hệ thống hóa kiến thức dễ hiểu, dễ nhớ và nhớ lâu; dùng kiến thức vừa thu lượm được để diễn đạt lại bài đọc hiểu và vận dụng nó vào cuộc sống; có ý kiến bàn luận về từng nội dung trong bài đọc hiểu (Đặng Thị Lan, 2009).

\section{Khách thể và phương pháp nghiên cứu}

Chúng tôi tiến hành khảo sát trên $506 \mathrm{SV}$ khóa 47 và khóa 48 thuộc các khoa: Khoa Sư phạm tiếng Anh (gọi tắt là khoa Anh), Khoa Ngôn ngữ và Văn hóa Nga (khoa Nga), Khoa Ngôn ngữ và Văn hóa Pháp (khoa Pháp), Khoa Ngôn ngữ và Văn hóa Trung Quốc (khoa Trung), Trường Đại học Ngoại ngữ ĐHQGHN.

Khách thể nghiên cứu cụ thể như sau:

Bảng 1. Số lượng sinh viên được khảo sát

\begin{tabular}{|c|c|c|c|c|c|c|}
\hline \multirow{2}{*}{ Khóa đào tạo } & Anh & Nga & Pháp & Trung & Chung \\
\hline \multirow{2}{*}{ Khóa 47 } & Số lượng & 77 & 42 & 68 & 52 & 239 \\
\cline { 2 - 7 } & $\%$ & 32,21 & 17,57 & 28,45 & 21,75 & 47,23 \\
\hline \multirow{2}{*}{ Khóa 48 4} & Số lượng & 84 & 36 & 83 & 64 & 267 \\
\cline { 2 - 7 } & $\%$ & 31,46 & 13,48 & 31,08 & 23,97 & 52,77 \\
\hline \multirow{2}{*}{ Tổng } & Số lượng & 161 & 78 & 151 & 116 & 506 \\
\cline { 2 - 7 } & $\%$ & 31,81 & 15,41 & 29,84 & 22,92 & 100,00 \\
\hline
\end{tabular}

Nghiên cứu được tiến hành bằng một hệ thống phương pháp: Phương pháp nghiên cứu lí luận, phương pháp điều tra viết, phương pháp quan sát, phương pháp phỏng vấn và phỏng vấn sâu..., trong đó điều tra viết là phương pháp chính nhằm thu thập thông tin về biểu hiện mức độ thích ứng với hoạt động học môn đọc hiểu tiếng nước ngoài của $\mathrm{SV}$ Trường Đại học Ngoại ngũ - ĐHQGHN.

Đánh giá mức độ thích ứng với hoạt động học môn đọc hiểu TNN của sinh viên Trường Đại học Ngoại ngữ - ĐHQGHN, chúng tôi dựa vào điểm cá nhân từng hành động học cơ bản để tính điểm tổng hợp về mức độ thích ứng với hoạt động học môn đọc hiểu TNN. Mức độ thích ứng với hoạt động học môn đọc hiểu TNN của $\mathrm{SV}$ được xếp theo ba mức: Thích úng cao (từ 8,0 điểm đến 10 điểm), thich úng trung bình (từ 5,0 điểm đến cận 8,0 điểm), thich íng thấp (dưới 5,0 điểm). 
4. Một vài kết quả nghiên cứu thực tiễn về biểu hiện mức độ thích ứng với hoạt động học môn đọc hiểu tiếng nước ngoài của $\mathrm{SV}$ Trường Đại học Ngoại ngũ̃ - ĐHQGHN

Bảng 2 cho thấy: Mức độ thích ứng với hoạt động học môn đọc hiểu TNN của $\mathrm{SV}$ Trường Đại học Ngoại ngữ - ĐHQGHN còn thấp, điểm trung bình chung là 4,79 , độ lệch chuẩn là 1,684 . Trong đó, hai hành động học có mức độ thích ứng cao hơn là chuẩn bị bài học và tiếp thu kiến thức bài học; hai hành động học có mức độ thích ứng thấp hơn là sử dụng GT và TLTK, chuẩn bị và tiến hành xêmina. Kết quả này phải chăng là do việc chuẩn bị và tiến hành xêmina ở bậc đại học còn mới mẻ đối với SV. Việc học ở đại học đòi hỏi SV không chỉ học theo vở ghi hoặc theo sách giáo khoa như ở phổ thông, mà còn bắt buộc họ phải đọc và nghiên cứu nhiều loại GT và TLTK. Để phân tích, đánh giá cụ thể hơn về biểu hiện mức độ thích ứng với hoạt động học môn đọc hiểu TNN, chúng tôi xem xét kết quả qua hai mặt nhận thức và thực hành từng hành động học cơ bản môn học này.

Bảng 2. Mức độ thích ứng với hoạt động học môn đọc hiểu TNN của sinh viên Trường Đại học Ngoại ngữ - ĐHQGHN

\begin{tabular}{|c|c|c|c|c|}
\hline TT & $\begin{array}{c}\text { Các hành động } \\
\text { học cơ bản }\end{array}$ & $\begin{array}{c}\text { Điểm trung } \\
\text { bình } \\
(1 \leq \bar{X} \leq £ 10)\end{array}$ & Thứ bậc & $\begin{array}{c}\text { Độ lệch } \\
\text { chuẩn }\end{array}$ \\
\hline 1 & Chuẩn bị bài học & 6,01 & 1 & 2,030 \\
\hline 2 & $\begin{array}{c}\text { Tiếp thu kiến } \\
\text { thức bài học }\end{array}$ & 5,69 & 2 & 2,628 \\
\hline 3 & $\begin{array}{c}\text { Sử dụng giáo } \\
\text { trình và tài liệu } \\
\text { tham khảo }\end{array}$ & 3,95 & 4 & 1,773 \\
\hline 4 & $\begin{array}{c}\text { Chuẩn bị và tiến } \\
\text { hành xêmina }\end{array}$ & 3,29 & 5 & 1,522 \\
\hline 5 & Ôn tập & 4,99 & 3 & 1,378 \\
\hline \multicolumn{2}{|c|}{ Tổng hợp } & 4,79 & 1,684 \\
\hline
\end{tabular}

- Chuẩn bị bài học môn đọc hiểu TNN:
Để thực hiện có kết quả một bài đọc hiểu $\mathrm{TNN}$, đòi hỏi $\mathrm{SV}$ phải có công tác chuẩn bị hết sức chu đáo về nội dung và cách thức trình bày. Thông thường $\mathrm{SV}$ có thời gian một tuần để tự lựa chọn bài đọc hiểu TNN với số lượng là 500 - 700 từ có liên quan đến nội dung chủ đề học tập và tóm tắt nội dung của bài đọc. Khi tiến hành bài đọc hiểu TNN, có từ ba đến bốn $\mathrm{SV}$ trực tiếp đọc bài đã chuẩn bị, sau đó có năm phút tóm tắt bài đọc hiểu, năm phút trả lời các câu hỏi của giảng viên và các $\mathrm{SV}$ trong lớp.

Có thể nói, chuẩn bị bài học môn đọc hiểu $\mathrm{TNN}$ là điều kiện thuận lợi để $\mathrm{SV}$ rèn luyện các kỹ năng đọc hiểu và làm phong phú thêm vốn từ vựng. Kết quả điều tra ở bảng 3 cho thấy: 91,69\% SV có chuẩn bị bài học môn đọc hiểu TNN nhưng chưa thường xuyên. So sánh với các hành động học khác thì hành động học này được $\mathrm{SV}$ nắm vững và thực hành tốt nhất (điểm trung bình là 5,91, độ lệch chuẩn là 2,030 - xem bảng 2).

Biểu hiện cụ thể của chuẩn bị bài học môn đọc hiểu TNN qua hai mặt nhận thức và thực hành như sau:

+ Về mặt nhận thức: Có 40,11\% SV hiểu đúng chuẩn bị bài học môn đọc hiểu TNN là học từ mới có liên quan đến chủ đề bài đọc hiểu, ôn cấu trúc ngữ pháp liên quan đến chủ đề bài đọc hiểu, tìm các nguồn tài liệu ở phạm vi chủ đề bài đọc hiểu và chủ đề hẹp do giảng viên qui định; $59,87 \% \mathrm{SV}$ chưa hiểu hoặc hiểu sai, họ cho rằng chuẩn bị bài học môn đọc hiểu TNN là chỉ thực hiện một trong những công việc trên.

Tác dụng của chuẩn bị bài học môn đọc hiểu TNN: Có 41,30\% SV hiểu đúng tác dụng của chuẩn bị bài học môn đọc hiểu TNN là giúp họ xác định đúng những nội dung chủ 
yếu cần tập trung học tập của chủ đề bài đọc hiểu; $58,69 \% \mathrm{SV}$ chưa nắm vững tác dụng của hành động học này, họ cho rằng tác dụng của nó là giúp họ hiểu và nắm được một số cấu trúc câu trong chủ đề của bài đọc hiểu trước khi lên lớp, giảm bớt dần thời gian trình bày của giảng viên về chủ đề bài đọc hiểu.

+ Về mặt thực hành: Để chuẩn bị bài học môn đọc hiểu TNN, sinh viên cần tập trung thực hiện các công việc: chuẩn bị đầy đủ các tài liệu cần thiết theo chủ đề bài đọc hiểu; xác định mối tương quan giữa kiến thức cũ và kiến thức mới, các thành phần cơ bản, những kiến thức trọng tâm của chủ đề bài đọc hiểu và tìm hiểu những kiến thức chưa nắm vững. Kết quả khảo sát thực tế cho thấy: Chỉ có $36,70 \% \mathrm{SV}$ đã thực hiện tốt những công việc trên, 57,59\% SV chưa thực hiện đầy đủ, chính xác công việc và $5,69 \% \mathrm{SV}$ không trả lời. Thực trạng này nói lên việc chuẩn bị bài học môn đọc hiểu TNN của SV còn nhiều hạn chế.

Bảng 3. Nhận thức và thực hành chuẩn bị bài học môn đọc hiểu TNN của sinh viên Trường Đại học Ngoại ngữ ĐHQGHN

\begin{tabular}{|c|c|c|c|c|}
\hline \multicolumn{2}{|c|}{ Biểu hiện } & $\begin{array}{c}\text { Nội dung, tác dụng và } \\
\text { công việc cụ thể của chuẩn } \\
\text { bị bài học }\end{array}$ & $\begin{array}{c}\text { Số } \\
\text { ý kiến }\end{array}$ & $\%$ \\
\hline \multirow{9}{*}{$\begin{array}{l}\text { Nhận } \\
\text { thức }\end{array}$} & \multirow{5}{*}{$\begin{array}{l}\text { Nội } \\
\text { dung }\end{array}$} & $\begin{array}{c}\text { Học từ mới có liên quan } \\
\text { đến chủ đề bài đọc }\end{array}$ & 80 & 15,81 \\
\hline & & $\begin{array}{c}\text { Ôn lại những cấu trúc câu } \\
\text { có liên quan đến chủ đề bài } \\
\text { đọc hiểu }\end{array}$ & 68 & 13,43 \\
\hline & & \begin{tabular}{|c|} 
Tìm các nguồn tài liệu phục \\
vụ chủ đề bài đọc hiểu
\end{tabular} & 155 & 30,63 \\
\hline & & Cả ba ý trên & 203 & 40,11 \\
\hline & & Tổng & 506 & 100,00 \\
\hline & \multirow{4}{*}{$\begin{array}{l}\text { Tác } \\
\text { dụng }\end{array}$} & $\begin{array}{l}\text { Hiểu và nắm một số cấu trúc } \\
\text { trong chủ đề bài đọc hiểu }\end{array}$ & 244 & 48,22 \\
\hline & & $\begin{array}{l}\text { Giảm bớt thời gian trình } \\
\text { bày của giảng viên }\end{array}$ & 53 & 10,47 \\
\hline & & $\begin{array}{l}\text { Xác định đúng nội dung } \\
\text { cần tập trung của chủ đề } \\
\text { bài đọc hiểu }\end{array}$ & 209 & 41,30 \\
\hline & & Tổng & 506 & 100,00 \\
\hline
\end{tabular}

\begin{tabular}{|c|c|c|c|}
\hline \multirow{1}{*}{ Có } & 474 & 93,67 \\
\cline { 2 - 4 } & Không & 30 & 5,92 \\
\cline { 2 - 4 } & Không trả lời & 2 & 0,39 \\
\cline { 2 - 4 } Thực hành & Tồng & 506 & 100,00 \\
\cline { 2 - 4 } & Thường xuyên & 188 & 39,66 \\
\cline { 2 - 4 } & Đôi khi & 249 & 52,53 \\
\cline { 2 - 4 } & ít khi & 37 & 7,80 \\
\cline { 2 - 4 } & Tổng & 474 & 100,00 \\
\cline { 2 - 4 } & $\begin{array}{c}\text { Thực hiện đúng một số } \\
\text { công việc cụ thể }\end{array}$ & 174 & 36,70 \\
\cline { 2 - 4 } & $\begin{array}{c}\text { Thực hiện chưa đúng một } \\
\text { số công việc cụ thể }\end{array}$ & 273 & 57,59 \\
\cline { 2 - 4 } & Không trả lời & 27 & 5,69 \\
\cline { 2 - 4 } & Tồng & 474 & 100,00 \\
\hline
\end{tabular}

Sinh viên Đàm Thị Minh Ch. lớp QH.2014.F1.C6 khóa 48 nói: "Chuẩn bị bài học môn đọc hiểu TNN vô cùng quan trọng cho việc học môn học này, nhung chỉ có khoảng hơn một phần ba số SV biết cách thưc hiện đúng nhũng công việc cần làm".

Như vậy, SV nhận thức và thực hành chuẩn bị bài học môn đọc hiểu TNN chưa cao, còn một bộ phận nhỏ SV chưa hiểu đúng hành động học này. Tìm hiểu nguyên nhân của thực trạng, $\mathrm{SV}$ cho biết: Về khách quan, các loại GT và TLTK phục vụ cho học tập của nhà trường còn thiếu và những tài liệu mới rất ít; nhiều $\mathrm{SV}$ khó khăn không có đủ kinh phí để mua GT và TLTK; một bộ phận giảng viên chưa đặt ra yêu cầu cao đối với $\mathrm{SV}$ trong việc chuẩn bị bài học; thiếu kiểm tra, đôn đốc, nhắc nhở hoặc kiểm điểm SV nếu không chuẩn bị bài. Về chủ quan, trong quá trình tự học, tự nghiên cứu, $\mathrm{SV}$ chưa chủ động khắc phục khó khăn của bản thân; không tích cực tư duy, tìm tòi, sáng tạo; phương pháp tự học và tự nghiên cứu không phù hợp; thậm chí có SV không quan tâm đến việc chuẩn bị bài học trước khi lên lớp...

- Tiếp thu kiến thức bài học môn đọc hiểu TNN:

Việc lĩnh hội kiến thức trong giờ học môn đọc hiểu TNN của SV Trường Đại học Ngoại ngữ 
- ĐHQGHN là không quá khó khăn như đối với SV các trường đại học khác khi học TNN. Tuy nhiên, SV nhận thức và thực hành hành động học này còn ở mức độ chưa cao (điểm trung bình là 5,69 và độ lệch chuẩn là 2,628 - xem bảng 2 ).

Bảng 4. Nhận thức và thực hành tiếp thu kiến thức bài học môn đọc hiểu TNN của sinh viên Trường Đại học Ngoại ngữ - ĐHQGHN

\begin{tabular}{|c|c|c|c|c|}
\hline \multicolumn{2}{|c|}{ Biểu hiện } & $\begin{array}{l}\text { Nội dung, tác dụng và } \\
\text { công việc cụ thể của tiếp } \\
\text { thu kiến thức bài học }\end{array}$ & $\begin{array}{l}\text { Số } \\
\text { ý kiến }\end{array}$ & $\%$ \\
\hline \multirow{9}{*}{$\begin{array}{l}\text { Nhận } \\
\text { thức }\end{array}$} & \multirow{4}{*}{$\begin{array}{l}\text { Nội } \\
\text { dung }\end{array}$} & $\begin{array}{l}\text { Tiếp thu tất cả những nội } \\
\text { dung trong bài đọc hiểu }\end{array}$ & 16 & 3,16 \\
\hline & & $\begin{array}{l}\text { Tiếp thu nội dung cụ } \\
\text { thể mà giảng viên đã } \\
\text { nhấn mạnh }\end{array}$ & 267 & 52,76 \\
\hline & & $\begin{array}{l}\text { Tiếp thu nội dung mà } \\
\text { bản thân thấy cần thiết } \\
\text { trong bài đọc hiểu }\end{array}$ & 223 & 44,07 \\
\hline & & Tổng & 506 & 100,00 \\
\hline & \multirow{5}{*}{$\begin{array}{l}\text { Tác } \\
\text { dụng }\end{array}$} & $\begin{array}{l}\text { Nắm được nội dung bài } \\
\text { đọc, hiểu ngay... }\end{array}$ & 42 & 8,30 \\
\hline & & $\begin{array}{l}\text { Trả lời những câu hỏi của } \\
\text { bài đọc hiểu, tóm tắt... }\end{array}$ & 122 & 24,11 \\
\hline & & $\begin{array}{l}\text { Có được những kiến } \\
\text { thức quan trọng... }\end{array}$ & 107 & 21,14 \\
\hline & & Cả ba ý trên & 235 & 46,44 \\
\hline & & Tổng & 506 & 100,00 \\
\hline \multirow{12}{*}{\multicolumn{2}{|c|}{ Thực hành }} & $\begin{array}{l}\text { Nguyên văn những nội } \\
\text { dung trong bài đọc hiểu }\end{array}$ & 47 & 9,28 \\
\hline & & Chỉ những nội dung chính & 344 & 67,98 \\
\hline & & $\begin{array}{l}\text { Cân nhắc và diễn đạt } \\
\text { theo ý riêng của mình }\end{array}$ & 115 & 22,72 \\
\hline & & Tổng & 506 & 100,00 \\
\hline & & Tiếp thu kịp & 157 & 31,02 \\
\hline & & Tiếp thu kịp và đầy đủ & 158 & 31,22 \\
\hline & & $\begin{array}{l}\text { Tiếp thu kịp, đầy đủ và } \\
\text { đúng }\end{array}$ & 191 & 37,74 \\
\hline & & Tổng & 506 & 100,00 \\
\hline & & $\begin{array}{l}\text { Giữ nguyên những nội } \\
\text { dung đã tiếp thu... }\end{array}$ & 142 & 28,06 \\
\hline & & $\begin{array}{l}\text { Đọc lại bài đọc hiểu để } \\
\text { chỉnh lí, bổ sung những } \\
\text { nội dung đã thu được }\end{array}$ & 213 & 42,09 \\
\hline & & $\begin{array}{l}\text { Đọc lại bài đọc hiểu để } \\
\text { chỉnh lí, bổ sung những } \\
\text { nội dung đã thu được và } \\
\text { tìm ra cấu trúc mới theo } \\
\text { ý riêng về từng nội dung } \\
\text { trong bài đọc hiểu }\end{array}$ & 151 & 29,84 \\
\hline & & Tổng & 506 & 100,00 \\
\hline
\end{tabular}

Bảng 4 cho thấy biểu hiện cụ thể của tiếp thu kiến thức bài học môn đọc hiểu TNN qua hai mặt nhận thức và thực hành như sau:

+ Về mặt nhận thức: Có nhiều cách hiểu khác nhau của $\mathrm{SV}$ về tiếp thu kiến thức trong giờ học môn đọc hiểu TNN. Nhóm nhiều nhất $(52,76 \%)$ là những $\mathrm{SV}$ hiểu tiếp thu kiến thức trong giờ học môn đọc hiểu TNN là chỉ tiếp thu một số nội dung cụ thể của bài đọc hiểu mà giảng viên đã nhấn mạnh. Nhóm ít nhất $(3,16 \%)$ là những $\mathrm{SV}$ hiểu tiếp thu kiến thức trong giờ học môn đọc hiểu TNN là tiếp thu tất cả thông tin trong bài đọc hiểu. Nhóm còn lại $(44,07 \%)$ là những SV hiểu đúng tiếp thu kiến thức trong giờ học môn đọc hiểu TNN là sự tiếp thu chủ động, tích cực để lĩnh hội các thông tin mà bản thân thấy cần thiết trong bài đọc hiểu.

Tác dụng của tiếp thu kiến thức trong giờ học môn đọc hiểu TNN: Chỉ có 46,44\% SV hiểu được tác dụng của hành động học này là giúp họ có khả năng nắm vững nội dung cơ bản của bài đọc hiểu và hiểu ngay trên lớp, trả lời những câu hỏi của bài đọc hiểu và tóm tắt nội dung bài đọc hiểu thành một đoạn văn ngắn, biết vận dụng kiến thức đã lĩnh hội vào cuộc sống.

+ Về mặt thực hành: Có 22,72\% SV tiếp thu kiến thức thông qua lựa chọn, xem xét, đánh giá và diễn đạt nội dung theo ý hiểu riêng của mình về chủ đề bài đọc hiểu; 37,74\% SV tiếp thu kiến thức kịp, đầy đủ và chính xác; 29,84\% SV biết đọc lại bài đọc hiểu để bổ sung, chỉnh lý và hoàn thiện kiến thức đã lĩnh hội và tìm cấu trúc câu mới theo ý riêng về từng nội dung trong bài đọc hiểu. Như vậy, vẫn còn một bộ phận không nhỏ SV chưa phát huy tính chủ động, tích cực, sáng tạo trong việc tiếp thu kiến thức bài học môn đọc hiểu TNN.

Sinh viên Nguyễn Phúc Cẩm Nh. lớp QH.2014.F1.E1 khóa 48 nói: “Tiếp thu kiến 
thức bài đọc hiểu TNN kịp, đầy đủ và chính xác không mấy dễ dàng đối với chúng em. Sau giờ học trên lớp, hầu hết các bạn đều xem lại bài đọc hiểu, nhung chỉ là bổ sung ý thiếu và chỉnh sưa nhũng ý chura chính xác. Việc hoàn thiện bài đọc hiểu bằng nhũng kiến thức tụ đọc được và tìm ra cấu trúc câu mới thì chúng em còn nhiều hạn chế".

- Ôn tập môn đọc hiểu TNN:

Ôn tập môn đọc hiểu TNN giúp SV am hiểu, củng cố, mở rộng kiến thức TNN đáp ứng yêu cầu nhiệm vụ học tập. Nhưng $\mathrm{SV}$ nắm vững và thực hành ôn tập môn học này ở mức độ thấp (điểm trung bình là 4,99 và độ lệch chuẩn 1,378 - xem bảng 2).

Bảng 5. Nhận thức và thực hành ôn tập môn đọc hiểu TNN của sinh viên Trường Đại học Ngoại ngũ̃ - ĐHQGHN

\begin{tabular}{|c|c|c|c|c|}
\hline \multicolumn{2}{|c|}{ Biểu hiện } & $\begin{array}{l}\text { Nội dung, tác dụng và công } \\
\text { việc cụ thể của ôn tập }\end{array}$ & $\begin{array}{c}\text { Số } \\
\text { ý kiến }\end{array}$ & $\%$ \\
\hline \multirow{8}{*}{$\begin{array}{l}\text { Nhận } \\
\text { thức }\end{array}$} & \multirow{4}{*}{$\begin{array}{l}\text { Nội } \\
\text { dung }\end{array}$} & $\begin{array}{c}\text { Ôn tất cả các bài đọc từ } \\
\text { trước đến nay }\end{array}$ & 73 & 14,42 \\
\hline & & $\begin{array}{l}\text { Ôn tất cả các bài đọc và } \\
\text { sếp theo mức độ khó khăn } \\
\text { tăng dần }\end{array}$ & 274 & 54,15 \\
\hline & & $\begin{array}{c}\text { Ôn các bài đọc trong mối } \\
\text { quan hệ thống nhất... }\end{array}$ & 159 & 31,42 \\
\hline & & Tổng & 506 & 100,00 \\
\hline & \multirow{4}{*}{$\begin{array}{l}\text { Tác } \\
\text { dụng }\end{array}$} & Giúp dễ nhớ & 169 & 33,39 \\
\hline & & Giúp dễ hiểu & 134 & 26,48 \\
\hline & & Cả hai ý trên & 203 & 40,11 \\
\hline & & Tổng & 506 & 100,00 \\
\hline \multirow{3}{*}{\multicolumn{2}{|c|}{ Thực hành }} & Thực hiện đúng các công viêc & 142 & 28,06 \\
\hline & & $\begin{array}{l}\text { Thực hiện không đúng các } \\
\text { công việc }\end{array}$ & 364 & 71,93 \\
\hline & & Tổng & 506 & 100,00 \\
\hline
\end{tabular}

Bảng 5 cho thấy biểu hiện cụ thể của ôn tập môn đọc hiểu TNN qua hai mặt nhận thức và thực hành như sau:

+ Về mặt nhận thức: Chỉ có 31,42\% SV hiểu đúng nội dung của ôn tập môn đọc hiểu TNN là nhằm củng cố, mở rộng, nâng cao kiến thức $\mathrm{TNN}$ và tìm ra mối quan hệ giữa các kiến thức đó. Số $\mathrm{SV}$ còn lại hiểu ôn tập môn đọc hiểu TNN là ôn tất cả các bài đọc từ trước đến nay; hoặc ôn tất cả các bài đọc từ trước đến nay và xếp theo mức độ khó tăng dần. Có $40,11 \% \mathrm{SV}$ thấy được tác dụng của ôn tập môn đọc hiểu TNN là giúp họ dễ hiểu, dễ nhớ, nhớ lâu và nâng cao kỹ năng, kỹ xảo sử dụng TNN.

+ Về mặt thực hành: Để ôn tập môn đọc hiểu TNN, sinh viên cần: làm các bài tập về từ vựng và ngữ pháp có liên quan đến bài đọc hiểu; chuẩn bị đề cương ôn tập môn đọc hiểu; thực hiện đúng mục đích, yêu cầu, nội dung của bài dạy đọc hiểu (đọc để lấy thông tin hay đọc để phân tích...); có ý kiến bàn luận về từng nội dung trong bài đọc hiểu... Thực tế nghiên cứu cho thấy còn quá nhiều $\mathrm{SV}(71,93 \%)$ chưa thực hiện đúng các công việc này.

Có thể nói, ôn tập môn đọc hiểu TNN là hành động học quen thuộc của $\mathrm{SV}$, nhưng nhiều SV nắm vững và thực hành nó còn rất kém. Nguyên nhân chủ yếu của vấn đề này là SV chưa biết lựa chọn và vận dụng phương pháp ôn tập phù hợp; tính chủ động, độc lập, sáng tạo trong ôn tập chưa cao.

Bảng 6. Nhận thức và thực hành sử dung GT và TLTK môn đọc hiểu TNN của sinh viên Trường Đại học Ngoại ngữ - ĐHQGHN

\begin{tabular}{|c|c|c|c|c|}
\hline \multicolumn{2}{|c|}{ Biểu hiện } & $\begin{array}{l}\text { Nội dung, tác dụng và } \\
\text { công việc cụ thể của sử } \\
\text { dụng GT và TLTK }\end{array}$ & $\begin{array}{c}\text { Số } \\
\text { ý kiến }\end{array}$ & $\%$ \\
\hline \multirow{7}{*}{$\begin{array}{l}\text { Nhận } \\
\text { thức }\end{array}$} & \multirow{3}{*}{$\begin{array}{l}\text { Nội } \\
\text { dung }\end{array}$} & Nhận thức đúng & 205 & 40,51 \\
\hline & & Nhận thức sai & 301 & 59,48 \\
\hline & & Tổng & 506 & 100,00 \\
\hline & \multirow{4}{*}{$\begin{array}{l}\text { Tác } \\
\text { dụng }\end{array}$} & $\begin{array}{c}\text { Rèn luyện kỹ năng đọc } \\
\text { lướt tốt }\end{array}$ & 211 & 41,69 \\
\hline & & $\begin{array}{l}\text { Đáp ứng yêu cầu môn học } \\
\text { trong chương trình }\end{array}$ & 106 & 20,94 \\
\hline & & \begin{tabular}{|c} 
Là hình thức chủ yếu để \\
tự học TNN theo kiểu \\
nghiên cứu
\end{tabular} & 189 & 37,35 \\
\hline & & Tổng & 506 & 100,00 \\
\hline
\end{tabular}




\begin{tabular}{|c|c|c|c|}
\hline & Có & 486 & 96,04 \\
\hline & Không & 20 & 3,95 \\
\hline & Tổng & 506 & 100,00 \\
\hline & Đọc đúng trình tự & 178 & 36,62 \\
\hline & Đọc không đúng trình tự & 308 & 63,37 \\
\hline & Tổng & 486 & 100,00 \\
\hline & Khi bắt đầu đoc & & \\
\hline & Đoc liền từ đầu đến cuối & 269 & 55,34 \\
\hline & Đọc lướt toàn bộ tài liệu & 31 & 6,37 \\
\hline & $\begin{array}{l}\text { Đọc lướt tìm ý chính, đọc } \\
\text { nhanh tìm các thông tin, } \\
\text { đọc suy luận để ghép các } \\
\text { thông tin lại cho phù hợp }\end{array}$ & 186 & 38,27 \\
\hline & Tổng & 486 & 100,00 \\
\hline & Sau khi đọc xong & & \\
\hline & $\begin{array}{c}\text { Nhớ và suy nghĩ về những } \\
\text { điều vừa đọc }\end{array}$ & 175 & 36,00 \\
\hline Thực hành & $\begin{array}{c}\text { Không nghĩ đến điều vừa } \\
\text { đọc, chuyê̂n sang công } \\
\text { việc khác }\end{array}$ & 52 & 10,69 \\
\hline & $\begin{array}{l}\text { Đọc lại đoạn mình thấy } \\
\text { hứng thú hoặc cần }\end{array}$ & 259 & 53,29 \\
\hline & Tổng & 486 & 100,00 \\
\hline & Ghi vào sổ tay & 213 & 43,82 \\
\hline & Ghi vào vở ghi & 58 & 11,93 \\
\hline & Ghi vào các tờ rời & 51 & 10,49 \\
\hline & Đánh dấu & 164 & 33,74 \\
\hline & Tổng & 486 & 100,00 \\
\hline & Có & 306 & 62,96 \\
\hline & Không & 180 & 37,03 \\
\hline & Tổng & 483 & 100,00 \\
\hline & Theo mức quan trọng & 78 & 25,49 \\
\hline & Theo tên tác giả & 27 & 8,82 \\
\hline & Theo chủ đề & 188 & 61,43 \\
\hline & Theo tên sách & 13 & 4,24 \\
\hline & Tổng & 306 & 100,00 \\
\hline
\end{tabular}

- Sủ dụng GT và TLTK môn đọc hiểu TNN:

Để giúp SV sử dụng tốt GT và TLTK môn đọc hiểu TNN, các khoa đào tạo đã xây dựng một hệ thống chủ điểm bài đọc hiểu tương đối toàn diện thuộc các lĩnh vực khác nhau, SV có thể lựa chọn những bài đọc hiểu phù hợp với nhu cầu, hứng thú và khả năng của họ. Mặc dù đã có công tác chuẩn bị chu đáo về nội dung, hướng dẫn phương pháp sử dụng GT và TLTK cho $\mathrm{SV}$, nhưng việc nắm vững và thực hành sử dụng GT và TLTK của họ chỉ đạt ở mức thấp (điểm trung bình là 3,95 và độ lệch chuẩn 1,773 - xem bảng 2).
Bảng 6 cho thấy biểu hiện cụ thể của sử dụng GT và TLTK môn đọc hiểu TNN qua hai mặt nhận thức và thực hành như sau:

+ Về mặt nhận thức: Có tới hơn một nửa SV (59,48\%) nhận thức sai, 40,51\% SV hiểu đúng, họ cho đây là hình thức tự học chủ yếu nhằm tích lũy tri thức ngôn ngữ đáp ứng yêu cầu nghiên cứu $\mathrm{TNN}$, cũng như nghiên cứu môn đọc hiểu TNN. Về tác dụng của hành động học này: có $37,35 \% \mathrm{SV}$ hiểu đúng đây là hình thức chủ yếu để tự học TNN có hiệu quả cao theo kiểu nghiên cứu.

+ Về mặt thực hành: Mỗi loại GT và TLTK có cấu trúc theo trình tự lô gíc chặt chẽ và chứa đựng một lượng kiến thức nhất định để cung cấp cho người đọc. Muốn lĩnh hội kiến thức trong GT và TLTK, đòi hỏi SV phải biết sử dụng nó một cách khoa học theo đúng qui trình. Kết quả điều tra cho thấy: Có $96,04 \% \mathrm{SV}$ sử dụng GT và TLTK môn đọc hiểu TNN, trong đó có 63,37\% $\mathrm{SV}$ đọc không theo qui trình, những $\mathrm{SV}$ biết cách đọc chiếm tỷ lệ thấp $(36,62 \%)$. Điều này chứng tỏ còn nhiều $\mathrm{SV}$ chưa biết cách đọc GT và TLTK môn đọc hiểu TNN.

Ngoài việc biết đọc GT và TLTK theo một trình tự đúng, khi bắt đầu đọc $\mathrm{SV}$ phải biết đọc lướt để tìm ý chính, đọc nhanh để tìm các thông tin, đọc suy luận để ghép các thông tin lại cho phù hợp... (chỉ có 38,27\% SV biết thực hiện thao tác này). Sau khi đọc xong, SV phải biết dành một khoảng thời gian nhất định để nhớ, suy nghĩ và vận dụng những điều vừa đọc (chỉ có 36,00\% SV biết thực hiện thao tác này).

Tiếp thu và lưu giữ thông tin là một công việc quan trọng, có ý nghĩa quyết định hiệu quả sử dụng GT và TLTK môn đọc hiểu TNN của SV. Những thông tin SV đã thu nhận được ghi lại và lưu giữ dưới nhiều hình thức khác nhau. Theo chúng tôi, cách ghi vào các tờ rời là thuận lợi và có hiệu quả nhất, nhưng kết quả nghiên cứu thu được thì chỉ có $10,49 \% \mathrm{SV}$ 
biết cách ghi và lưu giữ theo hình thức này; $43,82 \%$ SV ghi vào sổ tay; $33,74 \% \mathrm{SV}$ đánh dấu vào GT và TLTK; $11,93 \% \mathrm{SV}$ ghi vào vở ghi. Còn việc sắp xếp lại thông tin đã thu được thì chỉ có $62,96 \%$ SV thực hiện, trong đó có $61,43 \% \mathrm{SV}$ sắp xếp thông tin theo chủ đề để dễ bảo quản và sử dụng khi cần thiết.

Trần Thị L. lớp QH.2014.F1.F5 khóa 48 nói: "Chúng em biết mình cần phải đọc nhiều GT và TLTK bằng TNN để tư lự chọn bài đọc hiểu có liên quan đến chủ đề học tập, nhưng khi đọc còn nhiều bạn chura biết cách đọc và luu giũ thông tin".

Nhìn chung, đa số SV đã sử dụng GT và TLTK môn đọc hiểu TNN, trong đó bộ phận SV nắm vững và thực hành thành thạo hành động học này chiếm tỷ lệ thấp. Điều đó đã ảnh hưởng rất lớn đến mức độ thích ứng với hoạt động học môn đọc hiểu TNN của họ.

- Chuẩn bị và tiến hành xêmina môn đọc hiểu TNN:

Xêmina môn đọc hiểu TNN là hình thức tổ chức dạy học rất mới đối với SV. Sinh viên nắm vững và thực hành qui trình tiến hành xêmina ở mức thấp nhất (điểm trung bình là 2,49, độ lệch chuẩn là 1,522 - xem bảng 2).

Bảng 7 cho thấy biểu hiện cụ thể của chuẩn bị và tiến hành xêmina môn đọc hiểu TNN qua hai mặt nhận thức và thực hành như sau:

+ Về mặt nhận thức: Chỉ có 22,33\% SV hiểu đúng xêmina môn đọc hiểu TNN là hình thức tổ chức trao đổi, tranh luận một chủ đề khoa học dưới sự tổ chức, điều khiển của giảng viên. Số SV còn lại hiểu chưa đúng: 20,15\% SV hiểu xêmina môn đọc hiểu TNN là hình thức tổ chức trao đổi, tranh luận một chủ đề khoa học do SV tổ chức mà không có sự hướng dẫn của giảng viên; $57,51 \% \mathrm{SV}$ hiểu xêmina môn đọc hiểu TNN là hình thức tổ chức trao đổi, tranh luận một chủ đề khoa học do giảng viên tổ chức nhằm giúp $\mathrm{SV}$ củng cố, mở rộng và nâng cao kiến thức TNN đã học. Số SV hiểu đúng nhất tác dụng của xêmina là giúp SV rèn luyện tư duy khoa học, năng lực vận dụng kiến thức chỉ chiếm 18,57\%.

Bảng 7. Nhận thức và thực hành xêmina môn đọc hiểu TNN của sinh viên Trường Đại học Ngoại ngữ - ĐHQGHN

\begin{tabular}{|c|c|c|c|c|}
\hline \multicolumn{2}{|c|}{ Biểu hiện } & $\begin{array}{l}\text { Nội dung, tác dụng và } \\
\text { công việc cụ thể của chuẩn } \\
\text { bị và tiến hành xêmina }\end{array}$ & $\begin{array}{c}\text { Số } \\
\text { ý kiến }\end{array}$ & $\%$ \\
\hline \multirow{10}{*}{$\begin{array}{l}\text { Nhận } \\
\text { thức }\end{array}$} & \multirow{4}{*}{$\begin{array}{l}\text { Nội } \\
\text { dung }\end{array}$} & $\begin{array}{l}\text { Do SV tự tổ chức, không } \\
\text { có giảng viên hướng dẫn }\end{array}$ & 102 & 20,15 \\
\hline & & $\begin{array}{l}\text { Do giảng viên tổ chức để } \\
\text { giúp SV củng cố, mở rộng } \\
\text { và nâng cao kiến thức } \\
\text { TNN đã học }\end{array}$ & 291 & 57,51 \\
\hline & & $\begin{array}{l}\text { Về chủ đề khoa học liên } \\
\text { quan đến bài đọc hiểu }\end{array}$ & 113 & 22,33 \\
\hline & & Tổng & 506 & 100,00 \\
\hline & \multirow{6}{*}{$\begin{array}{l}\text { Tác } \\
\text { dụng }\end{array}$} & $\begin{array}{l}\text { Rèn luyện tính mạnh dạn, } \\
\text { khả năng diễn đạt ý kiến } \\
\text { bằng tiếng nước ngoài }\end{array}$ & 205 & 40,51 \\
\hline & & $\begin{array}{c}\text { Ôn tập, nắm chắc hơn kiến } \\
\text { thức của bài đọc hiểu }\end{array}$ & 109 & 21,54 \\
\hline & & $\begin{array}{l}\text { Rèn luyện tư duy khoa } \\
\text { học, năng lực vận dụng } \\
\text { kiến thức }\end{array}$ & 94 & 18,57 \\
\hline & & $\begin{array}{l}\text { Biết phân tích và trình bày } \\
\text { vấn đề bằng TNN }\end{array}$ & 96 & 18,97 \\
\hline & & Không trả lời & 2 & 0,39 \\
\hline & & Tổng & 506 & 100,00 \\
\hline \multirow{9}{*}{\multicolumn{2}{|c|}{ Thực hành }} & Từ nhiều nguồn kiến thức & 169 & 33,39 \\
\hline & & Trả lời sai và không trả lời & 337 & 66,60 \\
\hline & & Tổng & 506 & 100,00 \\
\hline & & $\begin{array}{c}\text { Thực hiện đúng các công } \\
\text { việc }\end{array}$ & 175 & 34,58 \\
\hline & & $\begin{array}{l}\text { Thực hiện không đúng các } \\
\text { công việc }\end{array}$ & 331 & 65,41 \\
\hline & & Tổng & 506 & 100,00 \\
\hline & & $\begin{array}{l}\text { Thực hiện đúng trình tự } \\
\text { các bước }\end{array}$ & 127 & 25,09 \\
\hline & & $\begin{array}{l}\text { Thực hiện không đúng } \\
\text { trình tự các bước }\end{array}$ & 379 & 74,90 \\
\hline & & Tổng & 506 & 100,00 \\
\hline
\end{tabular}

+ Về mặt thực hành: Để chuẩn bị tốt đề cương xêmina môn đọc hiểu TNN, sinh viên phải biết huy động kiến thức từ nhiều nguồn tài liệu: từ những thông tin thu được trong bài đọc hiểu TNN, từ GT và TLTK, từ những tư liệu tự sưu tầm được. Thực tế, chỉ có 33,39\% 
SV biết lựa chọn nguồn kiến thức để chuẩn bị xêmina. Ngoài ra, $\mathrm{SV}$ còn phải biết thực hiện theo trình tự các bước: 1/ Nghiên cứu kỹ thông tin có liên quan đến chủ đề xêmina; $2 /$ Xây dựng cấu trúc đề cương xêmina; 3 / Sắp xếp, trình bày thông tin về chủ đề theo cấu trúc đã định; 4/Chuẩn bị ý kiến tham gia tranh luận. Kết quả thực tế cho thấy chỉ có $34,58 \%$ $\mathrm{SV}$ thực hiện đúng trình tự các bước này. Như vậy, việc thu thập thông tin, thực hiện các bước chuẩn bị và tiến hành xêmina môn đọc hiểu TNN của SV còn hạn chế. Sinh viên Phan Tố $Q u$. lớp QH.2014.F1.R1 khóa 48 nói: "Thật khó khăn khi chuẩn bị và tiến hành xêmina môn đọc hiểu TNN bởi lẽ chúng em hiểu còn rất mo hồ về nội dung cu thể cũng nhu nhũng công việc cần làm khi thực hiện nó...".

Như vậy, trong các hành động học cơ bản môn đọc hiểu TNN có một số hành động học được $\mathrm{SV}$ nhận thức và bước đầu thực hành tốt hơn các hành động học khác như: chuẩn bị bài học và tiếp thu kiến thức bài học. Nhìn chung, mức độ nhận thức và thực hành từng hành động học môn đọc hiểu TNN của SV Trường Đại học Ngoại ngũ̃ - ĐHQGHN còn thấp.

\section{Kết luận và ý kiến đề xuất}

Kết quả nghiên cứu thực tiễn biểu hiện mức độ thích ứng với hoạt động học môn đọc hiểu TNN của SV Trường Đại học Ngoại ngữ - ĐHQGHN qua mặt nhận thức về bản chất, nội dung cụ thể, tác dụng của các hành động học cơ bản và mặt thực hành các hành động học cho thấy: Sinh viên đã có hiểu biết cơ bản về bản chất, nội dung cụ thể, tác dụng của các hành động học cơ bản và thực hành có hiệu quả những công việc chủ yếu của các hành động học đó, tuy rằng kết quả chưa cao. Một số hành động học cơ bản của môn đọc hiểu tiếng nước ngoài như: chuẩn bị bài học, tiếp thu kiến thức bài học được SV nhận thức và thực hành ở mức độ trung bình; các hành động học cơ bản khác như sử dụng GT và TLTK, chuẩn bị và tiến hành xêmina thì mức độ nhận thức và thực hành của $\mathrm{SV}$ còn thấp.

Từ kết quả nghiên cứu trên, chúng tôi xin đề xuất một số ý kiến nhằm giúp $\mathrm{SV}$ nâng cao nhận thức và thực hành thành thạo hơn các hành động học cơ bản môn đọc hiểu TNN:

- Các khoa đào tạo cần tổ chức giới thiệu cho SV phương pháp học môn đọc hiểu TNN, tạo điều kiện để SV tổ chức các câu lạc bộ TNN...

- Giảng viên dạy môn đọc hiểu TNN cần cung cấp cho SV những hiểu biết về nội dung, tác dụng của các hành động học cơ bản của môn học và hướng dẫn cho các em cách thực hành các hành động học đó, tăng thời gian thực hành để SV rèn luyện các hành động học cơ bản này.

- Sinh viên cần có nhận thức đúng về nội dung, tác dụng của các hành động học cơ bản của môn đọc hiểu TNN, tích cực rèn luyện các hành động học đó trong quá trình học TNN.

\section{Tài liệu tham khảo}

Đỗ Thị Châu (1999). Nghiên cứu kỹ năng đọc hiểu tiếng Anh của học sinh lớp 6. Luận án tiến sỹ khoa học Sư phạm tâm lí, Trường Đại học Sư phạm Hà Nội, Hà Nội.

Đặng Thị Lan (2009). Mức độ thích ứng với hoạt động học một số môn học chung và môn đọc hiểu tiếng nước ngoài của sinh viên trường Đại học Ngoại ngữ - Đại học Quốc gia Hà Nội. Luận án tiến sỹ khoa học Sư phạm tâm lí, Trường Đại học Sư phạm Hà Nội, Hà Nội.

Đặng Thị Lan (2013). Mức độ thích ứng với hoạt động học môn đọc hiểu tiếng nước ngoài của sinh viên trường Đại học Ngoại ngũ - Đại học Quốc gia Hà Nội. Tạp chí Khoa học Đại học Quốc gia Hà Nội, Số 3.

Trần Hữu Luyến (2008). Co' sở tâm lí học day học ngoại ngũ. Nxb Đại học Quốc gia Hà Nội, Hà Nội. 


\title{
EXPRESSIONS OF LEVEL OF ADAPTATION TO STUDENTS' LEARNING ACTIVITIES IN READING FOREIGN LANGUAGES AT UNIVERSITY OF LANGUAGES AND INTERNATIONAL STUDIES, VIETNAM NATIONAL UNIVERSITY, HANOI
}

\author{
Dang Thi Lan
}

\author{
Division of Educational Psychology, VNU University of Languages \\ and International Studies, Pham Van Dong, Cau Giay, Hanoi, Vietnam
}

\begin{abstract}
This study has shown some basic theoretical issues such as foreign language learning activities, level of adaptation to learning activities in reading foreign languages, expressions of level of adaptation to learning activities in reading foreign languages in terms of perception, content, the effect of 5 basic learning actions and their practice. Practical results showed that even not at high level, ULIS - VNU students acquired the basic understandings of the nature, the detailed content and the effects of basic learning actions, and practiced them effectively. Several basic learning actions such as preparation for lessons and the perception of knowledge were at average level; the other basic learning actions such as exploring course books and reference materials, preparing and conducting seminars were at low level in terms of perception and practice.
\end{abstract}

Keywords: learning activities in reading foreign languages, reading foreign languages, expressions of level of adaptation, ULIS - VNU students 